\title{
Interpretation of Tracer Displacement During Infiltration of River Water to Groundwater
}

\author{
Eduard HoeHN
}

\author{
Swiss Federal Institute for Reactor Research, Würenlingen, Switzerland
}

Peter H. Santschi

\author{
Swiss Federal Institute for Water Resources and Water Pollution Control, Dübendorf, Switzerland
}

\begin{abstract}
The accidental release of a tritium pulse of about $500 \mathrm{Ci}$ into a river in northern Switzerland allowed the measurement of travel times at a site where the river recharges a granular aquifer almost perpendicularly to the groundwater flow. A series of sampling wells had been previously installed in the aquifer. Most wells give access to shallow freshly infiltrated water. The infiltrated water flows along in the top layer of the aquifer, thus allowing for a one-dimensional analysis of the spreading process from the river to the groundwater in the wells. The linear groundwater flow velocities calculated from the tritium responses at distances from the river of up to $500 \mathrm{~m}$ confirm the velocities determined from an earlier local-scale uranine experiment at the same site. The scarce data used to describe tracer transport in the aquifer allowed for an assessment of dispersivity with the method of moments. A linearly scale-dependent dispersivity is evaluated from the mode of increase of the temporal variance of the tracer concentration distribution. Some wells revealed bimodal responses; here the method of moments is applied in combination with a two-layer model.
\end{abstract}

\section{INTRODUCTION}

The processes governing the movement of nonreactive tracers in groundwater, advection and hydrodynamic dispersion, are reasonably well understood in homogenous porous media. The classical theory assumes advection and dispersion to be constant in time and space at the scale of the representative elementary volume (REV) [e.g., Bear, 1979, chapter 7]. Within the concept of the REV, dispersivity is defined as a "local" property, at the scale of the pores. In most field experiments, however, the strength of the spreading of a tracer mass is known to depend on aquifer inhomogeneities of a scale larger than that of the pores. On the macroscopic aquifer scale, macrodispersive flux is governed by the hydraulicconductivity distribution [Mercado, 1967; Pickens and Grisak, 1981; Gelhar and Axness, 1983]. An additional mechanism producing the spreading of a tracer cloud is the screening of sampling wells over considerable vertical distances [Pickens and Grisak, 1981]. Values for the "macroscopic" dispersivity resulting from field-scale observations in granular aquifer formations increase with travel distance or travel time at a given site, as the macrodispersion process develops [Fried, 1975; Sudicky et al., 1983; Dieulin et al., 1981;. Molz et al., 1983]. Values for macrodispersivity may also depend on the technique used in spatial averaging; in such cases, they are of limited value for predictive modeling.

Recent advances in dispersion theory provide a basis for the estimation of macrodispersivity from the variability of the hydraulic conductivity (HC) of an aquifer [e.g., Gelhar and Axness, 1983]. The application of this theory requires extensive measurements of the aquifer's "effective" $\mathrm{HC}$ tensor using, e.g., flow meters in sampling wells [Hufschmied, 1986] or permeameter tests of core materials [Sudicky, 1986]. In studies of

Copyright 1987 by the American Geophysical Union.

Paper number 5W4117.

$0043-1397 / 87 / 005 W-4117 \$ 05.00$ groundwater contamination, however, we often do not have sufficiently large sets of $\mathrm{HC}$ data. The difficulty of the spatial averaging is circumvented with extensive three-dimensional tracer observations using either multilevel point samplers [Pickens et al., 1978] or bundle piezometers [Cherry et al., 1983]. In poorly graded aquifers, such as perialpine glaciofluvial outwash deposits, these techniques are, however, not feasible, because wells need a gravel packing around the piezometer pipes.

An alternate approach is the method of moments (MOM) [e.g., Fischer et al., 1979, chap. 2]. It can be used to observe the strength of the tracer spreading at different scales. The method utilizes the variance of the concentration distribution and is valid for any pulselike input of mass [Aris, 1958]. It has successfully been used by Beltaos and Day [1978] to describe the temporal spreading of tracer clouds in a stream with an irregular sinusoidal pattern. Gelhar et al. [1985] noted that the MOM is advantageous in that it does not make the a priori assumption that the dispersivities are constant in time and space.

In heterogenous aquifers, many breakthrough response curves are multimodal and exhibit extended trailing edges. Kreft et al. [1974] and Gaillard et al. [1977], for example, separated : overall response curves into partial curves, assuming that the aquifer consists of different layers. They considered dispersivity to be constant, according to the classical advection-dispersion theory.

In this paper we present results from the observation of an accidental release of tritium (half life 12.35 years) into an aquifer-recharging river. The accident allowed us to monitor the recharging of the aquifer at groundwater sampling wells using the tritium as a tracer. We neglect isotopic exchange between the tritium in the groundwater and the bound water, e.g., with $\mathrm{OH}$ groups sorbed at clay minerals, as this reservoir is small compared to that of the advecting water. The wells are situated at distances between 26 and $500 \mathrm{~m}$ along flow lines almost perpendicularly to the bank. The tritium release is then. compared with the results of a preceding uranine dye tracer 
experiment in the same aquifer portion at two sampling wells. These wells are situated at distances of 4.4 and $10.4 \mathrm{~m}$ from the river bank. We discuss the use of the MOM to identify the nature of the macroscopic dispersion parameter as a basis for the simulation of tracer breakthrough.

\section{Extension of the Advection-Dispersion Principle}

Consider the advection-dispersion equation (ADE) in porous media on the REV scale in one dimension [e.g., Bear, 1979, equation (7-49)]. An analytical solution to this equation, which conforms with the response to a pulse stimulus of a conservative tracer in an infinite or a semi-infinite uniform velocity field, is given as the normal probability-density function of the travel time distribution expressed in the units of concentration

$$
C(x, t)=Y(4 \pi D t)^{-1 / 2} \exp \left[-(x-\bar{v} t)^{2} / 4 D t\right]
$$

where

$C$ tracer concentration $\left(\mu \mathrm{Ci} / \mathrm{m}^{3} ; \mathrm{mg} / \mathrm{m}^{3}\right)$;

$x$ travel distance $(\mathrm{m})$;

$t$ time (day);

$D$ coefficient of hydrodynamic dispersion $\left(\mathrm{m}^{2} / \mathrm{d}\right)$;

$\bar{v}$ average linear groundwater flow velocity defined in a Darcy flow system as $q / n(\mathrm{~m} / \mathrm{d})$;

$n$ aquifer porosity;

$q$ specific discharge, or Darcy velocity, derived from Darcy's law as $q=J K\left(\mathrm{~m}^{3} \mathrm{~m}^{-2} \mathrm{~d}^{-1}\right)$;

$J$ constant hydraulic gradient;

$K$ horizontal component of the effective $\mathrm{HC}$ tensor along flow line $(\mathrm{m} / \mathrm{d})$.

In typical applications, $D$ and $\bar{v}$ are assumed to be constants in (1) and are related to each other by [e.g., Bear, 1979, equation (7-4)]

$$
D=\alpha_{l} \bar{v}
$$

where $\alpha_{l}$ is the local aquifer longitudinal dispersivity (m); $\bar{v}$ is equivalent to $\bar{x} / \bar{t}$, where $\bar{x}$ is the mean travel distance; and $\bar{t}$ is the mean travel time.

The parameter $Y$ refers to the initial condition. We discuss this parameter with the respective boundary conditions for the infinite and the semi-infinite flow field [Kreft and Zuber, 1978]. In the case of an infinite flow field,

$$
Y=m / n F
$$

$\left(\mu \mathrm{Ci} / \mathrm{m}^{2} ; \mathrm{mg} / \mathrm{m}^{2}\right)$, where $m$ is the amount of tracer injected $(\mu \mathrm{Ci} ; \mathrm{mg}) ; F$ is the cross-sectional area of bed $\left(\mathrm{m}^{2}\right)$; and $n F$ is the cross-sectional area of flow. The initial condition prescribed for the infinite flow field is $C(x, 0)=Y \delta(x)$, where $\delta(x)$. is the Dirac delta function in space. The boundary condition for this flow field is $\lim C(x, t)=0$ as $\rightarrow \pm \infty$. In the case of a semi-infinite flow field,

$$
Y=(m / Q)(x / t)
$$

$\left(\mu \mathrm{Ci} / \mathrm{m}^{2} ; \mathrm{mg} / \mathrm{m}^{2}\right)$, where $Q$ is the volumetric flow rate through $\operatorname{bed}\left(\mathrm{m}^{3} / \mathrm{d}\right)$, and $(m / Q)=\int_{0}^{\infty} C(t) d t$. The initial condition prescribed for the semi-infinite flow field is $C(0, t)=Y \delta(t)$, where $\delta(t)$ is the Dirac delta function in time. The boundary conditions for this flow field are $C(x, 0)=0$ for $x>0$, and lim $C(x, t)=0$ as $x \rightarrow \infty$. In many tracer studies, $(m / Q)$, in the solution to $(3 b)$, can easily be calculated by integrating the area under the curve interpolated from the concentration history. This solution gives a better fit to experimental data than with (3a), but it does not conserve mass [Zuber, 1974].
Dispersivity as a Function of Travel Distance or Travel Time

The local dispersivity as defined in (2) has been used with some success in laboratory experiments. It is, however, of little practical meaning for the characterization of field-scale tracer distributions. At the field scale, tracer distributions are mainly governed by the variability of $\mathrm{HC}$, and dispersivity is known to be growing with increasing travel distance or travel time. For the characterization of the dispersion process at the field scale, the local dispersivity should be embedded in the more general term of macrodispersivity $A_{l}$ [e.g., Gelhar and Axness, 1983]. To analyze whether the dispersivities are constant or linearly growing with travel distance or travel time, we resorted to the MOM. This alternative method is independent of the ADE, and we thus avoided some of the problems associated with the model calibrations [Gelhar et al., 1985].

\section{The Second Spatial Moment of a Tracer Distribution}

Constant dispersivity has been presented in terms of the spatial variance or second spatial moment of a tracer distribution $\sigma_{x}^{2}$ as [e.g., Bear, 1961]

$$
A_{l}=1 / 2\left(d \sigma_{x}^{2} / d \bar{x}\right)
$$

Gelhar et al. [1985] have shown that for a constant $A_{l}, \sigma_{x}{ }^{2}$. versus $\bar{x}$ plots as a straight line with the slope $m$, and $A_{l}=$ $\mathrm{m} / 2$. From (4), a distance-dependent dispersivity can be defined as

$$
A_{i}(\bar{x})=1 / 2\left(d \sigma_{x}^{2} / d \bar{x}\right)
$$

In the case where $A_{t}$ is linearly dependent on $\bar{x}$,

$$
A_{i}(\bar{x})=\alpha \bar{x}+\beta
$$

where $\alpha$ and $\beta(L)$ are constants. Integrating (4) with $A_{e}$ and combining (4) with the linear function (6), the derivative of $\sigma_{x}^{2}$ over $\bar{x}^{2}$ is

$$
d \sigma_{x}^{2} / d \bar{x}^{2}=2 \alpha+\beta / \bar{x}
$$

Neglecting the second term, which is permissible for high values of $\bar{x}, \sigma_{x}{ }^{2}$ versus $\bar{x}^{2}$ plots as a straight line with the slope $2 \alpha . A_{l}$ can then be expressed as

$$
A_{l}=2 \alpha \bar{x}
$$

\section{The Second Temporal Moment of a \\ Tracer Distribution}

The experimental results described in this paper are based on concentration variations as a function of travel time at a few sampling wells, rather than as a function of travel distance. Thus the spreading process should be described by the temporal variance or second temporal moment of a tracer distribution $\sigma_{t}{ }^{2}$. The relationship between $\sigma_{t}{ }^{2}$ and $\sigma_{x}{ }^{2}$ has theoretically been investigated by Tsal and Holley [1978] for tracer distributions in open channels. Applying the Taylor hypothesis the authors assumed that

$$
\sigma_{t}^{2} \sim \sigma_{x}^{2} / \bar{v}^{2}
$$

Equation (9) is an approximation valid for constant dispersivities at relatively large values, when the difference between dimensionless temporal and spatial variances approaches a constant value, and when the dimensionless variance is large relative to this constant difference [T sai and Holley, 1978].

From the above we present a constant dispersivity in terms 


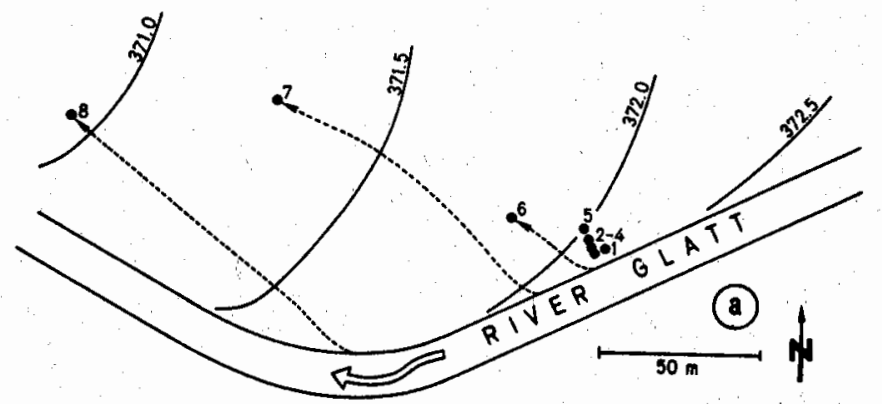

Fig. 1. Location and layout of the field study site [Hoehn et al., 1983]. (a) Solid circles indicate sampling wells; solid curves are lines of equal potential, interpreted from readings at 24 areally distributed piezometers; dashed curves are flow lines. (b) Dashed lines. show screened sections of the sampling wells. Distances from the river are as follows: well $1,2.5 \mathrm{~m}$; well $2,5 \mathrm{~m}$; well $3,7 \mathrm{~m}$; well $4,9 \mathrm{~m}$; well 5 , $13 \mathrm{~m}$; well $6,26 \mathrm{~m}$; well $7,100 \mathrm{~m}$; well $8,110 \mathrm{~m}$; well 9, $500 \mathrm{~m}$. Width of the river is $18 \mathrm{~m}$.

of the temporal derivative of $\sigma_{t}^{2}$ using (4) and (9) as

$$
A_{l} \sim \bar{v} / 2\left(d \sigma_{\imath}{ }^{2} / d \bar{l}\right)
$$

If $\bar{v}$ can be assumed to be constant, $\sigma_{t}{ }^{2}$ versus $\bar{t}$ plots as a straight line with the slope $m$, and $A_{1}=\overline{\mathrm{v}} \mathrm{m} / 2$.

We take (10) to be used with sufficient accuracy for timedependent dispersivities for the purpose of investigating scarce observation data. $A_{l}$ can then be defined from (10) as

$$
A_{l}(t) \sim \bar{v} / 2\left(d \sigma_{t}^{2} / d \bar{t}\right)
$$

In the case where $A_{t}$ is linearly dependent on $\bar{t}$,

$$
A_{i}(\bar{t})=\alpha \bar{t}+\beta
$$

where $\alpha$ and $\beta$ are constants with the units $(L / T)$ and $(L)$, respectively. Equations (11) and (12) yield

$$
\sigma_{t}{ }^{2} \sim\left(2 \alpha \bar{t}^{2}+\beta \bar{t}\right) / \bar{v}
$$

The derivative of $\sigma_{t}^{2}$ over $t^{2}$ is

$$
d \sigma_{t}{ }^{2} / d \bar{t}^{2} \sim 2 \alpha / \bar{v}+\beta / \bar{v} \bar{t}
$$

The second term can be neglected at high values of $\bar{t}$, and $\sigma_{t}{ }^{2}$ versus $\vec{t}^{2}$ plots then as a straight line with the slope $(2 \alpha / \vec{v})$, and
$A_{l}$ can be expressed as

$$
A_{l} \sim(2 \alpha / \vec{v}) \bar{t}
$$

Equations (10) through (15) are analogous to (4) through (8).

In Darcy flow systems, the linear groundwater flow velocity is defined at the REV scale as is HC. In many tracer distribution studies, it is, however, averaged over the screened length of the sampled wells. The above analogy holds under the requirement that the depth-averaged flow velocity $\bar{v}$ is constant from well to well.

\section{EXPERIMENTAL}

An experimental well field was installed 1979 in the lower Glatt valley, Switzerland (Figure $1 a$ ) to study the behavior of contaminants during infiltration of river water to groundwater [Schwarzenbach et al., 1983; Kull and von Gunten, 1986]. The PVC piezometer pipes in wells $1-8$ have a diameter of either 2 or $4,1 / 2$ inches and are screened with rows of slots. The screens of most of the wells are situated in the uppermost part of the saturated aquifer, which is penetrated, primarily, by freshly infiltrated water (Figure 1b). They extend over short vertical distances, depending somewhat on the fluctuating groundwater table. The water supply well 9 is located about $1000 \mathrm{~m}$ downstream of the experimental site. It has a diameter of the screened tubes of $1.6 \mathrm{~m}$ and is pumped every half day at a rate of about $2600 \mathrm{~m}^{3} / \mathrm{day}$. Measurements with a turbinetype flow meter [Hufschmied, 1986] showed vertical currents of $2-5 \mathrm{~m}^{3} / \mathrm{d}$ in the pipes of wells 2 and 8 . Vertical flow is common in many wells of perialpine outwash aquifer formations. Because of vertical flow, it was not possible to unambiguously sample water from a specific depth, within the screened section of a pipe.

The aquifer consists of tightly packed glaciofluvial outwash deposits which are $25-30 \mathrm{~m}$ thick. Core material from the wells 1,2 , and 6 , recovered during the drilling operations, showed interbedded and nonuniformly graded fine and coarse layers of sand and gravel (Figure $1 b$ ). Lenses of fine material extend horizontally over $2-20 \mathrm{~m}$, as is known from the study of local gravel pits. Values of $\mathrm{HC}$ given from measurements at three wells near those shown in Figure 1 are presented in Table 1. These wells are situated in a triangle of about $8 \mathrm{~m}$ equal length and are $10-15 \mathrm{~m}$ deep. The methods described in

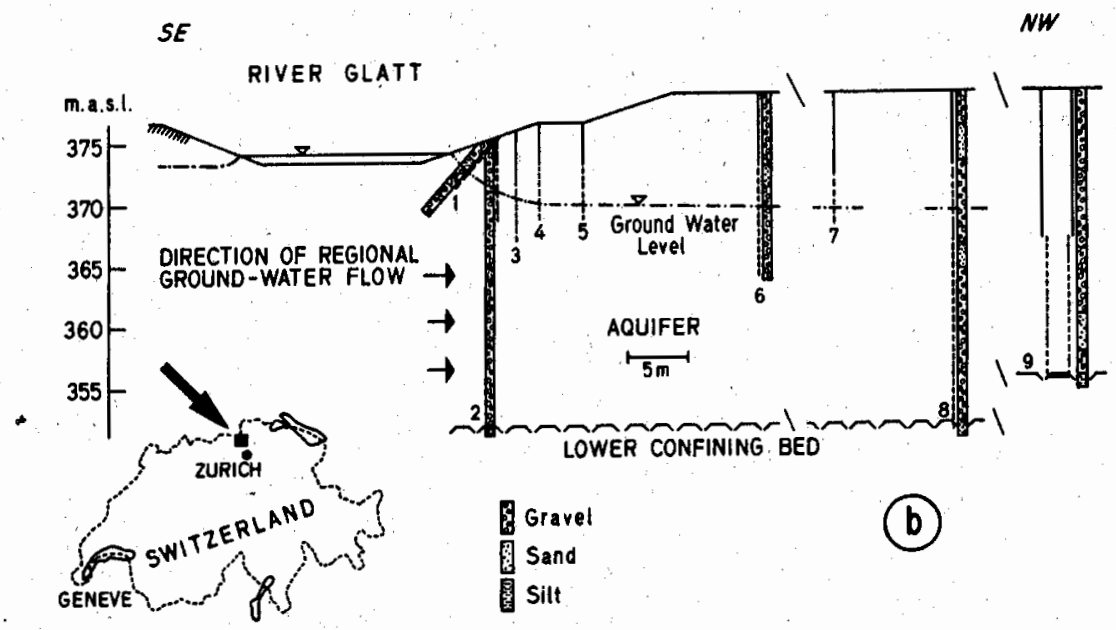

Fig. 1b 
TABLE 1. Aquifer Hydraulic Conductivity Testing

\begin{tabular}{|c|c|c|c|c|}
\hline Test & $\underset{\mathbf{m}}{\Delta}$ & $\begin{array}{c}d, \\
\text { meters above } \\
\text { sea level }\end{array}$ & $\underset{\mathrm{m} / \mathrm{d}}{K}$ & $\begin{array}{l}\ln K \\
\ln \mathrm{m} / \mathrm{d}\end{array}$ \\
\hline 1 & 0.4 & 371.0 & , 103 & 4.63 \\
\hline 2 & 0.4 & 370.6 & 103 & 4.63 \\
\hline 3 & 0.2 & 370.4 & 79.4 & 4.37 \\
\hline 4 & 0.2 & 370.2 & 79.4 & 4.37 \\
\hline 5 & 0.2 & 370.0 & 158 & 5.06 \\
\hline 6 & 0.2 & 369.8 & 569 & 6.34 \\
\hline 7 & 0.2 & 369.6 & 312 & 5.74 \\
\hline 8 & 0.1 & 367.6 & 33.6 & 3.51 \\
\hline 9 & 0.1 & 366.1 & 38.4 & 3.65 \\
\hline 10 & 0.3 & 365.1 & 202 & 5.31 \\
\hline 11 & 0.1 & 362.9 & 216 & 5.38 \\
\hline 12 & 0.2 & 361.9 & 432 & 6.07 \\
\hline 13 & 0.1 & 368.0 & $<7$ & 1.95 \\
\hline 14 & 0.1 & 366.8 & 28.8 & 3.36 \\
\hline 15 & 0.3 & 365.5 & 64.8 & 4.17 \\
\hline 16 & 0.2 & 364.7 & 14.6 & 2.68 \\
\hline 17 & 0.3 & 363.5 & 57.6 & 4.05 \\
\hline 18 & 0.2 & 361.8 & 50.4 & 3.92 \\
\hline
\end{tabular}

Method of the tests $1-6$ (well KB3, $b=1.8 \mathrm{~m}$ ): pumping tests from the intervals $\Delta z$ in the completed sampling tube, combined with flow meter measurements [Hufschmied, 1986]. Method of the tests 8-18 (well KBS, $b=6.1 \mathrm{~m}$, tests 8-12; well KB6, $b=9.0 \mathrm{~m}$, tests $13-18$ ): cased-hole pumping tests during drilling of the well at the depth $d$ with an uncased section $\Delta z$ below the casing [Dachler, 1936]. Here, $\Delta z$, length of tested interval; $d$, depth at which test was performed; $K$, horizontal component of hydraulic conductivity; and $b$ length of the screened section.

Table 1 probably yield the horizontal component of the effective $\mathrm{HC}$ assuming horizontal layers of a constant $\mathrm{HC}$. A mean value was found to be at about $K=90 \mathrm{~m} / \mathrm{d}$. No trend of $\mathrm{HC}$ is found in vertical direction. A lognormal distribution of $\mathrm{HC}$ in vertical direction is suggested for aquifers of the same stratigraphic unit by $\mathrm{Hufschmied}$ [1986].

The average discharge of the river Glatt is approximately $700,000 \mathrm{~m}^{3} / \mathrm{d}$ of which $15-20 \%$ is effluent from a number of biomechanical sewage treatment plants. The river recharges the aquifer at a rate of $0.4-0.8 \mathrm{~m}^{3} / \mathrm{d}$ per unit infiltration area

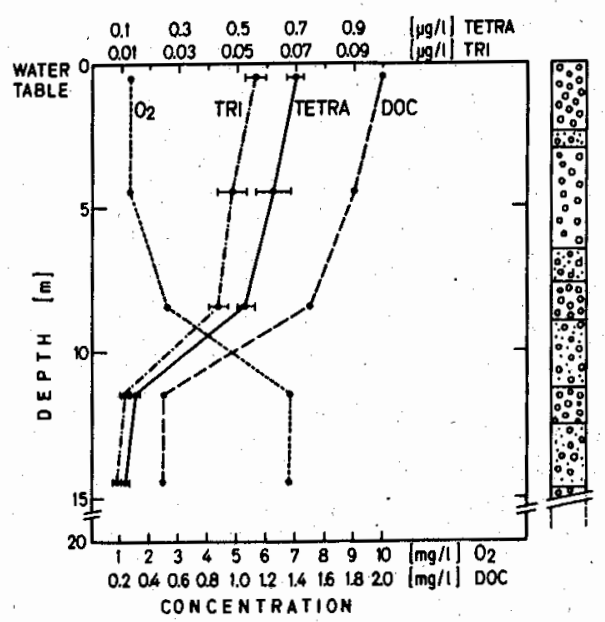

Fig. 2. Vertical concentration profiles of selected parameters in well 8 and a schematic geological profile [Schwarzenbach et al., 1983]: short-dashed curves, dissolved oxigen $\left(\mathrm{O}_{2}\right)$; long-dashed curves, dissolved organic carbon (DOC); solid curves, tetrachloroethylene (tetra); dashed-dotted curves, trichloroethylene (tri); circles, mainly gravel; circles and dots, gravel and sand, respectively (reprinted with permission from Environmental Science Technology, Copyright 1983, American Chemical Society). $q_{a}\left(7-15 \mathrm{~m}^{3} / \mathrm{d}\right.$ per unit river length), through an inflow "seepage face" with a high hydraulic gradient, mainly at the right river bank. The seepage face is saturated throughout most of the year. We interpreted the natural distribution of hydraulic head and probable flow lines (Figure 1 a) from readings at 24 areally distributed piezometers to yield an average gradient away from the river of about $0.6 \%$. A thickness $(b)$ of $7-15 \mathrm{~m}$ in the uppermost part of the saturated aquifer is permeated by freshly infiltrated water $\left(b=q_{a} / q ; q=1 \mathrm{~m} / \mathrm{d}\right)$. The results of a vertical chemical profile revealed little vertical mixing below the infiltration zone at about $10 \mathrm{~m}$ depth (Figure 2), which compares well with the value of $b$ as calculated above. We neglected mixing as a result of seepage because recharge from the surface in this region is only about $0.04 \mathrm{~m} /$ year, which is about 3 orders of magnitude less than the contribution from the river.

On December 13,1983, a pulse of about $500 \mathrm{Ci}$ of tritiated water (about $0.1 \mathrm{~m}^{3}$ of volume) was accidentally released into a sewer of an industrial firm, reaching, with a mean travel time of about 1 day, a municipal sewage treatment plant. The travel time of the tritium in the river, from the plant's outlet to the infiltration field site, was about 9 hours. The tritium pulse was modulated by the sewage treatment plant and by the river before it appeared at the experimental site. An additional temporal spread of the tracer cloud was possible due to infiltration of river water through the bed and the left bank. Unfortunately, sampling of the wells did not start until 6 days following the release. Grab samples were collected from near the groundwater table, without prior purging of the well, except for the pumped well 9 , and analyzed with standard liquid scintillation counters (detection limit $0.1 \mu \mathrm{Ci} / \mathrm{m}^{3}$ ). The natural background activity concentration in the area is about 0.2 $\mu \mathrm{Ci} / \mathrm{m}^{3}$. The effects of the tritium spill on surface waters and on the groundwater of several drinking water supply wells in the region are reported elsewhere (P. H. Santschi et al., unpublished manuscript, 1986).

About 4 years earlier, a simple tracer experiment was made with five grams of uranine (color index 45340). The results of this experiment are correlated with the results of the tritium

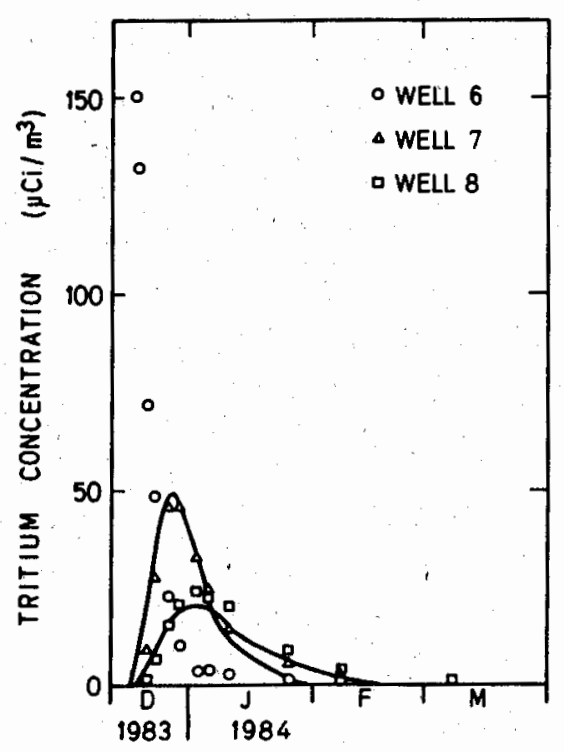

Fig. 3. Tritrium breakthrough in the wells of the experimental field. Curves represent simulations using the method of moments explained in the text. The first data point of well 6 was assumed to be at peak concentration. 


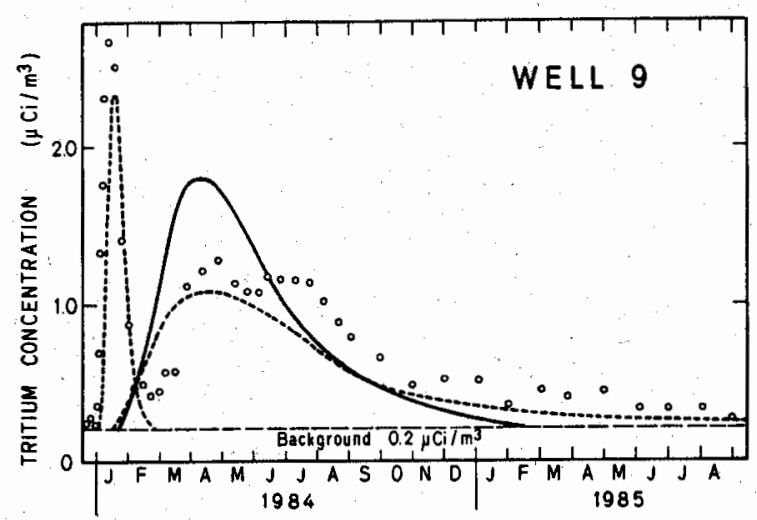

Fig. 4. Tritium breakthrough in the production well 9. Solid curves represent a simulation using the method of moments; dashed curves represent a simulation using a combination of the two-layer model and the method of moments. Both simulations are explained in the text.

spill accident (see below). The uranine tracer was dissolved in $2 \mathrm{~L}$ of tap water and injected into the inclined well 1 . It was mixed with well water for $5 \mathrm{~min}$ to ensure a homogenous concentration. About $\mathbf{9 0} \%$ of the tracer mass has moved out of the input well within 3 hours. The groundwater from wells $2-5$ was then continuously pumped at rates of about 0.7 $\mathrm{m}^{3} / \mathrm{day}$, which is of the order of the discharge through the vertical cross section of the screened length of the well at natural gradient conditions. The samples were analyzed with a spectrofluorometer (Kontron, type 22) at 490/520 nm (detection limit $0.5 \mathrm{mg} / \mathrm{m}^{3}$ ). We considered both tracers (tritium and uranine) to be conservative for the purpose of the present investigation.

\section{Results AND Discussion}

\section{Interpretation of the Observed Responses}

The release of tritiated water into the river Glatt resulted in responses at all of the wells shown in Figure 1. The sampling of well 6 started probably at about the time of maximum concentrations (see Figure 3). A complete breakthrough was observed in wells 7-9, shown in Figures 3 and 4 . Well 9 revealed a bimodal breakthrough, the second appearing about 3 months after the first. The unimodal responses of wells 7 and 8 to the tritium spill must not necessarily document transport through one aquifer layer only; they could also represent an averaging effect of the large scale of observation. We did not interprete the trailing edges of the responses at the wells 1-6, situated at distances less than $26 \mathrm{~m}$ from the river bank.

Natural gradient linear groundwater flow velocities corresponding to the mean travel times range from 4 to $6 \mathrm{~m} / \mathrm{day}$; 5-30 $\mathrm{Ci}$ of tritium must have infiltrated into the aquifer. This was assessed by multiplying $m / Q$ from $(3 b)$ at the wells 7 and 8 with the infiltration recharge rate. The loss of tritium from the river to the ground water compares quite well with the percentage loss of river water due to infiltration [Hoehn et al., 1983].

The earlier uranine experiment resulted in complete and bimodal breakthrough responses at the wells 3 and 5 , as shown in Figures $5 a$ and $5 b$, respectively. The breakthrough was interpreted to be due to flow through the two gravel layers of different $\mathrm{HC}$ and the less permeable sandy layer found in the cores of wells 1 and 2 (see Figure $1 b$ ). No response was detected in well 2 in the 9-day observation period as it may not be situated along a flow line, and between wells 1 and 4 , the lack of response is likely because of the occurrence of fine-grained material of a poorer HC than that of the gravelly formation. Two and $5 \%$ of the tracer mass were recovered from the wells 3 and 5 , respectively. The difference may be due to the fact that well 3 has a somewhat larger screened section and is diluted with untraced groundwater. Average travel times for uranine of 3.0 and 3.3 days correspond to flow velocities of about 1 and $3 \mathrm{~m} / \mathrm{d}$ at wells 3 and 5 , respectively. These travel times are slightly lower than those measured for tritium at the wells 7 and 8 .

\section{Modeling the Plumes in One Dimension}

The scarcity of data forced us to make simplifying assumptions for the analysis of the two plumes (tritium and uranine) If these assumptions are justified, it is possible to analyze the tracer data in terms of one-dimensional flow. The recharging river is regarded as a line source in the horizontal plane for the freshly infiltrated water. The response in the aquifer domain recharged by the river to the tritium spill conforms with the boundary condition requirements (equation $(3 b)$ ) of a semi-infinite flow field for the solution (1) of the ADE. In this domain, the flow lines are assumed to be straight and parallel, and the hydraulic gradient is assumed to be constant. We neglected concentration gradients in the horizontal transverse direction because of the line-source type upstream boundary.
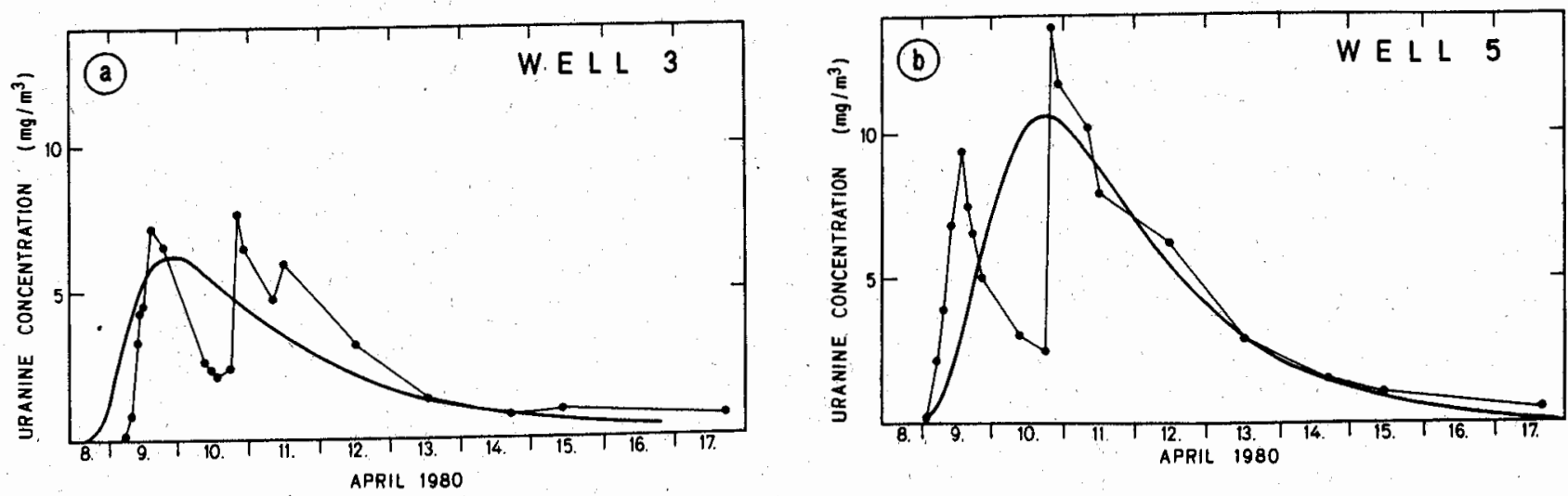

Fig. 5. Uranine breakthrough in the wells of the experimental field. Curves represent simulations using the method of moments explained in the text; thin solid curves are drawn to guide the eye. 
TABLE 2. Results of Breakthrough Observations

\begin{tabular}{|c|c|c|c|c|c|c|}
\hline Well & $\begin{array}{c}\bar{t}, \\
\text { day }\end{array}$ & $\begin{array}{c}\sigma_{f}^{2}, \\
\mathbf{d}^{2}\end{array}$ & $\begin{array}{l}m / Q, \\
\mu \mathrm{Ci} \mathrm{d} \mathbf{d}^{-1} \mathbf{m}^{-3}, \\
\mathrm{mg} \mathrm{d}^{-1} \dot{m}^{-3}\end{array}$ & $\begin{array}{l}\bar{x}^{*}, \\
\text { m }\end{array}$ & $\begin{array}{l}\bar{x} / \bar{t} \\
\mathrm{~m} / \mathrm{d}\end{array}$ & $\begin{array}{c}A_{t}^{\dagger}, \\
\mathrm{m}\end{array}$ \\
\hline & \multicolumn{6}{|c|}{ Uranine Experiment } \\
\hline 3 & 3.0 & 3.4 & 19 & 4.4 & 1.5 &.$\quad 1.1$ \\
\hline 5 & 3.3 & 5.5 & 32 & 10.4 & 3.2 & 1.2 \\
\hline \multicolumn{7}{|c|}{ Tritium Accident } \\
\hline 7 & 18 & $1.5 \times 10^{2}$ & 740 & 100 & $5.6^{\circ}$ & 6.7 \\
\hline 8 & 28 & $2.5 \times 10^{2}$ & 530 & 110 & 3.9 & 10 \\
\hline 9 & 158 & $1.2 \times 10^{4}$ & 240 & 500 & 3.2 & 58 \\
\hline
\end{tabular}

*Calculated from the flow lines in Figure $1 a$.

$\dagger A_{1}=(2 \alpha / v) \tilde{t} ;(2 \alpha / \bar{v})=0.37 ; \bar{v}=3.5 \pm 1.5 \mathrm{~m} / \mathrm{d}$ (see Figure 6).

We neglected concentration gradients in the vertical direction because the results shown in Figure 2 revealed little mixing between the sampled water of freshly infiltrated origin and older water of a different chemical composition. Possible effects of both horizontal transverse and vertical macrodispersion are lumped in the concentration versus travel time data together with the effects of longitudinal macrodispersion. This simplified approach can, to a small extent, provide artificially inflated values for the spreading process in one dimension [Domenico and Robbins, 1984]. However, Klotz et al. [1980] reported ratios of longitudinal to vertical dispersivity of over 100 from experiments in glaciofluvial outwash deposits of Bavaria of similar sedimentological properties as the one described here.

The uranine experiment is based on different initial conditions than the tritium spill accident. The input well 1 may be regarded as a line source in the vertical direction. However, the screens of this well reached only about $1 \mathrm{~m}$ into the saturated aquifer, by the time of the experiment. We did not account for this difference in the light of the scarce data available, and we applied the same simplifications as were underlain to the one-dimensional analysis of the tritium data. It is obvious that such an analysis has to be taken with more reservations in the case of the uranine experiment.

\section{Application of the Moment Method}

to the Tracer Data

A summary of tracer observations and analyses are presented in Table 2. The time variance $\sigma_{t}{ }^{2}$ grows with the mean travel time $\bar{t}$. We calculated a mean flow velocity $\bar{v}$ to be $3.5 \pm 1.5 \mathrm{~m} / \mathrm{d}$ using the five wells. A linear regression showed a dependence of the temporal variance on the square of mean travel time. The graphical presentation of the regression on a $\log$-log scale in Figure $6 a$ exhibits a slope of about two, while the slope in Figure $6 b$ is about one. The axial intercept in the $\log -\log$ scale of Figure $6 a$ represents the value of $m$ in the case of a constant dispersivity, and that of Figure $6 b$ represents $2 \alpha / \bar{v}$, the slope of a graph of $A_{t}$ versus $\bar{t}$ in (15). If we allow $d \sigma_{t}{ }^{2} / d \vec{t}^{2}$ in (14) to be higher by $10 \%$ because we negiected the second term of this equation, the constant $\beta$ in this dropped term must not exceed a value of $0.43 \mathrm{~m}$ for $\bar{t}=3.0$ days, or 2.6 $\mathrm{m}$ for $\bar{t}=18$ days, given that $2 \alpha / \bar{v}=0.37$ in both cases. The dispersivities of the given aquifer portion and the given completion of the wells, calculated using (15), and shown in Table 2 , extend from 1.1 to $58 \mathrm{~m}$. These values and their mode of increase conform with the data points of many other field experiments in granular aquifer formations given by, for example, Lallemand-Barrès and Peaudecerf [1978], Schröter [1984], and Gelhar et al. [1985].

The values of dispersivity in Table 2 have been assessed solely. from the analysis of the spread of the tracer breakthrough. We used these values in (1) with a semi-infinite flow field for a simulation of the breakthrough to compare with the observed data of Figures 3-5. While the simulations fit reasonably well with the tritium data in the experimental field, they fit less well with wells 3 and 5 (uranine experiment) and well 9 (production well), which revealed bimodal breakthrough responses. The MOM as outlined above does not account for the representation of more than one peak. Such tracer distributions can be exploited with a two-layer model, if two layers are present in the examined aquifer portion. The multilayer model of Zuber [1974], for example, consists of separating the experimental response into partial responses. The overall mean travel time is calculated from individual mean travel times $\bar{t}_{i}$ as $\bar{t}=\sum_{i=1}{ }^{n}\left(R_{i} \bar{t}_{i}\right)$, where $R_{i}$ is the partial relative recovery from layer $i$ defined by $Z$ uber [1974, equation (15)] as

$$
C_{N}(t) d t=R_{i} \int_{0}^{\infty} C(t) d t
$$

Table 3 shows an analysis of the tritium observations at well 9 with the two-layer approach. The existence of two layers may be supported from the core $\log$ of well 9 (Figure $1 b$ ), but the
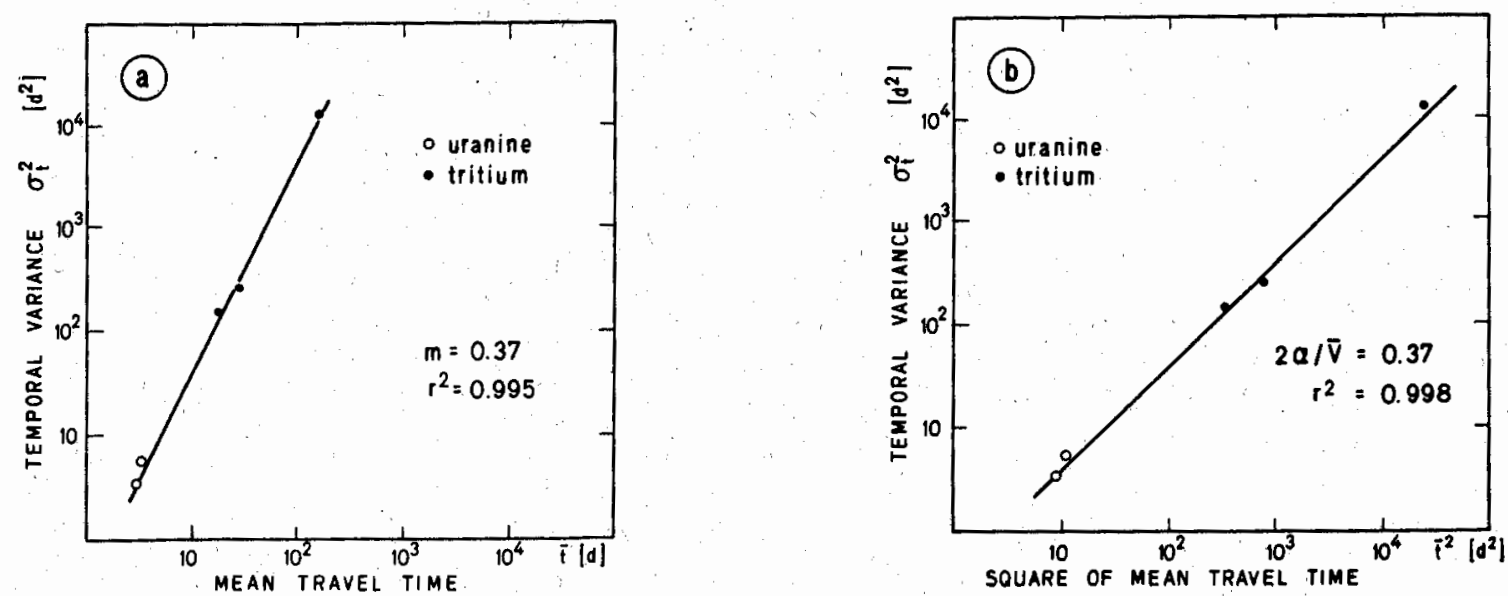

Fig. 6. Dependence of the temporal variance on (a) the mean travel time and $(b)$ on the square of the mean travel time, both shown at a log-log scale. 
INBI,I: 3. Results of Breakthrough Observations at Well 9 Using the Two-Layer Model of Zuber [1974]

\begin{tabular}{|c|c|c|c|c|c|c|}
\hline Lalyer & d & $\sigma_{1}^{2}$ & $\mu \mathrm{Ci} \mathrm{d}^{-1} \mathrm{~m}^{-3}$ & $R^{*}$ & $\begin{array}{l}\bar{x} / \bar{t} \\
\mathrm{~m} / \mathrm{d}\end{array}$ & $\underset{m}{A_{l} \dagger}$ \\
\hline I & 33 & $1.8 \times 10^{2}$ & 79 & 0.18 & 15 & 12 \\
\hline 2 & 220 & $1.8 \times 10^{4}$ & 161 & 0.82 & 2.3 & 81 \\
\hline
\end{tabular}

* Partial recovery split chosen by eye at 46 days (end February 1984).

$+A_{1}=(2 \alpha / \vec{v}) \bar{l}($ see Table 2 and Figure 6$)$.

infiltration of river water from different sites upstream or infiltration from both sides of the bank could have produced the same effect. We used the dispersivities from Table 3 for breakthrough simulations assuming that the relationship shown in Figure $6 b$ is valid also for partial recoveries. These simulations are plotted against the breakthrough data and compared with the simulation of the regular MOM in Figure 4. It is of no surprise that the curve-fitting procedure generated by adding a floating parameter $R_{i}$ leads to a better simulation. Though the use of the two-layer approach might also be justified in the case of wells 3 and 5, we did not make the effort because of the doubtful one-dimensional nature of the uranine experiment.

We are aware of the fact that many assumptions are made in the analysis of this field study and that some of them may result in an erroneous interpretation of the observed data. If the variances of the concentration distributions are inflated because we neglected the effects of concentration gradients in the horizontal and vertical transverse directions, this will consequently result in enhanced values for dispersivity. If a single experiment is designed with synchronous observations at all wells, the travel time distributions will probably be different from those observed. If the initial spread of the tracer was known at its point of entry to the aquifer, values for dispersivity would result which are different from those calculated. If the screened length of the wells is much shorter, multimodel responses could, perhaps, be avoided.

\section{CONCLUSIONS}

The accidental release of about $500 \mathrm{Ci}$ of tritium into a river in northern Switzerland was not designed to act as a tracer experiment. State authorities would never have allowed such a release of radioactivity. We monitored wells in the groundwater of a layered glaciofluvial outwash aquifer to check for the consequences of the accident' on the aquatic environment, rather than to verify transport model assumptions. This is often the case in groundwater contamination problems. The tracer pulse produced travel time distributions as it moved down the river. Tritium results were compared with the observations of an earlier uranine tracer experiment. As the granular texture of the aquifer allowed for neither point measurements of hydraulic conducitivity nor point-sampling techniques, the data to describe tracer transport in the aquifer were too scarce and not adequate for a comprehensive analysis of the dispersion process. Consequently, our interpretations depended on the averaging produced by the length of the filter screens of the wells.

The field observations ranged over about 2 orders of magnitude in tracer concentrations and over almost 2 orders of magnitude in mean tracer travel time. They verified the recently developed theory that a classical gradient-flux relationship is not valid. The method of moments in time described the spreading process of the tritium plume sufficiently well, while the results from the local-scale uranine experiment fit less well. It allows the calculation of variable dispersivities. From the mode of increase of the temporal variances we concluded that the dispersivity is linearly scale-dependent over mean travel times of up to about 150 days corresponding to mean travel distances of up to about $500 \mathrm{~m}$.

The simulation of the bimodal breakthrough responses with the two-layer model of $Z$ uber [1974] required the partial relative recovery as an additional floating parameter. We doubt that this method can be used to predict breakthrough responses other than the ones observed because the effect will vary with the nature of the aquifer and the length of the screened sections of wells.

Acknowledgments. Financial support for the research was partly granted by the Swiss National Science Foundation. We thank those involved in the field work for their assistance. We acknowledge the critical comments made by N. H. Brooks, L. W. Gelhar, and B. Honeyman.

\section{REFERENCES}

Aris, R., On the dispersion of linear kinematic waves, Proc. $R$. Soc. London, Ser. A, 245, 268-277, 1958.

Bear, J., On the tensor form of dispersion in porous media, J. Geophys. Res., 66(4), 1185-1197, 1961.

Bear, J., Hydraulics of Groundwater, McGraw-Hill, 569 pp., New York, 1979.

Beltaos, S., and T. J. Day, A field study of longitudinal dispersion, Can. J. Civ. Eng., 5, 572-585, 1978.

Cherry, J. A., R. W. Gillham, E. G. Anderson, and P. E. Johnson, Groundwater monitoring devices, J. H ydrol., 63, 113-126, 1983.

Dachler, R., Grundwasserströmung, Springer-Verlag, New York, 1936.

Dieulin, A., Propagation de pollution dans un aquifère alluvial, L'effet de parcours, Houille Blanche, 26(1), 9-14, 1981.

Domenico, P. A., and G. A. Robbins, A dispersion scale effect in model calibrations and field tracer experiments, $J$. Hydrol., 70, 123132, 1984.

Fischer, H. B., E. J. List, R. C. Y. Koh, J. Imberger, and N. H. Brooks, Mixing in inland and coastal waters, Academic, 483 pp., Orlando, Fla., 1979.

Fried, J. J., Groundwater pollution, in Developments in Water Science, vol. 4, edited by V. T. Chow, 330 pp., Elsevier Science, New York, 1975.

Gaillard, B., D. Rousselot, and J. P. Sauty, Application d'une Méthode économique de détermination sur le terrain des paramètres de dispersion, paper presented at Proceedings, IAHR Symposium on Hydrodynamic Diffusion and Dispersion in Porous Media, Int. Assoc. for Hydraul. Res., Pavia, Italy, 1977.

Gelhar, L. W., and C. L. Axness, Three-dimensional stochastic analysis of macrodispersion in aquifers, Water Resour. Res., 19(1), 161$180,1983$.

Gelhar, L. W., A Mantoglou, C. Welty, and K. R. Rehfeldt, A review of field-scale physical solute transport processes in saturated and unsaturated porous media, Rep. RP-2485-05, Electr. Power Res. Inst., Palo Alto, Calif., 1985.

Hoehn, E., J. Zobrist, und R. P. Schwarzenbach, Infiltration von Flusswasser ins Grundwasser-Untersuchungen im Nahbereich der Glatt, Gas Wasser Abwasser, 63(8), 401-410, 1983.

Hufschmied, P., Estimation of three-dimensional statistically anisotropic hydraulic conductivity field by means of single-well pumping tests combined with flow-meter measurements, Bull. Bur. Res. Geol. Miner., 2, 163-174, 1986.

Klotz, D., K. P. Seiler, H. Moser, and F. Neumaier, Dispersivity and velocity relationships from laboratory and field experiments, $J$. Hydrol, 45(1/2), 169-184, 1980.

Kreft, A., and A. Zuber, On the physical meaning of the dispersion equation and its solutions for different initial and boundary conditions, Chem. Eng. Sci., 33, 1471-1480, 1978.

Kreft, A.; A. Lenda, B. Turek, A. Zuber, and K. Czauderna, Determination of effective porosities by the two-well pulse method, in Isotope Techniques in Groundwater Hydrology, vol. 2, pp. 295-312, IAEA, Vienna, 1974.

Kull, T., and H. R. von Gunten, Infiltration of inorganic compounds from a river into a groundwater aquifer, Water Air Soil Pollut., 29, 333-346, 1986. 
Lallemand-Barrès, $A$, and $P$. Peaudecerf, Recherche des relations entre la valeur de la dispersivité macroscopique d'un milieu aquifère, ses autres caractéristiques et les conditions de mesure, Bull. Bur. Rech. Geol. Min., Sect. 3, 3(4), 277-284, 1978.

Mercado, A., The spreading pattern of injected water in a permeability stratified aquifer, Publ. 82, pp. 23-36, Int. Assoc. of Hydrol. Sci., Gentbrugge, Belgium, 1967.

Molz, F. J., O. Güven, and J. G. Melville, An examination of scaledependent dispersion coeflicients, Groundwater, 2l(6), 715-725, 1983.

Pickens, J. F., and G. E. Grisak, Scale-dependent dispersion in a stratified granular aquifer, Water Resour. Res., 17(4), 1191-1211, 1981 :

Pickens, J. F., J. A. Cherry, G. E. Grisak, W. F. Merritt, and B. A. Risto, A multilevel device for groundwater sampling and piezometric monitoring, Groundwater, 16(5), 322-327, 1978.

Schröter, J., Mikro- und Makrodispersivität poröser Grundwasserleiter, Meyniana, 36, 1-34, 1984.

Schwarzenbach, R. P., W. Giger, E. Hoehn, and J. K. Schneider Behavior of organic pollutants during infiltration of river water to ground water, Field Studies, Environ. Sci. Technol., 17(8), 472-479, 1983.
Sudicky, E. A., A natural gradient experiment on solute transport in a sand aquifer: Spatial variability of hydraulic conductivity and its role in the dispersion process, Water Resour. Res., 22(13), 2069. $2082,1986$.

Sudicky, E. A., J. A. Cherry, and E. O. Frind, A natural gradient dispersion test, J. Hydrol, 63, 81-108, 1983.

Tsai, Y. H., and E. R. Holley, Temporal moments for longitudinal dispersion, J. Hydraul. Eng., 104(HY12), 1617-1634, 1978.

Zuber, A., Theoretical possibilities of the two-well pulse method, Isotope Techniques in Groundwater Hydrology, Rep. IAEA-SMI82/45, pp. 277-294, IAEA, Vienna, 1974.

E. Hoehn, Department of Chemistry, Swiss Federal Institute for Reactor Research, 5303 Würenlingen, Switzerland.

P. H. Santschi, Radiology Section, Swiss Federal Institute for Water Resources and Water Pollution Control, 8600 Dübendorf, Switzerland.

(Received April 22, 1985 ;

revised December 24, 1986;

accepted December 30,1986.) 